\title{
Volatility Spillover In Stock And Commodity Futures Market: Empirical Analysis In Indonesia's Financial Market
}

\author{
Siti Saadah, Teresia Angelia dan Kusumahadi \\ Fakultas Ekonomi dan Bisnis-Unika Atmajaya Jakarta \\ siti.saadah@atmajaya.ac.id
}

\begin{abstract}
Volatility spillover between stock markets causes insignificancy of diversification. Therefore, other investment alternatives is required to build an optimal portfolio, one of them being commodity futures. The low correlation between commodity futures and stocks indicates the advantage of diversification in investment portfolio containing both assets. In order to prove the advantage of diversification, author tested the existence of volatility spillover during September 16, 2010 - September 30, 2015. Estimation result using GARCH method indicates the presence of significant volatility spillover from stock exchange to commodity futures exchange. An important implication of this finding is that if the sectoral stock index and commodity futures are incorporated into an investment portfolio, the investor will not have optimal diversification advantage. This is because there is a correlation between performance of both markets as a result of both markets having the same characteristics in response to the shock that is coming.
\end{abstract}

Keywords: Volatility spillover; stock; commodity futures; financial market; GARCH.

\section{INTRODUCTION}

An investment is the current commitment of money or other resources in the expectation of reaping future benefits (Bodie, Kane, \& Marcus, 2008). The invested assets can be in the form of real asset or financial asset; such as stock and bond. With the development of knowledge and economy in Indonesia, financial assets become an increasingly prominent type of asset and widely used in investing. As a financial product, financial assets continue to experience growth, including a continuously emerging variety of derivative products. Derivative products thrive to anticipate and take advantage of inherent uncertainties in financial markets.

Commodity futures is one of derivative asset, whose prices are determined by or "derive from" other securities (Bodie, Kane, \& Marcus, 2008). Unlike the stock which is used to raise the fund and cause investor to bear the risk, commodity futures allows firm to obtain insurance for the future value of their outputs or input (Gorton \& Rouwenhorst, 2006). Investors in commodity futures will receive compensation for bearing the risk of short-term commodity price fluctuations (Gorton \& Rouwenhorst, 2006). Although commodity futures is not widely known as stocks or bonds, it has a significant function as a hedging tool for investors that cannot be denied.

In addition to functioning as a hedging tool, commodity futures can be used by investors as a safe haven. Moreover, it is also known to have a low correlation with stocks. This is because the factors that influence commodity prices (e.g., weather and geopolitical conditions, supply constraints in the physical production, and event risk) are distinct from those that determine the value of stocks.(Daskalaki \& Skiadopoulos, 2011). The investment portfolio containing commodity futures and stocks will result in greater 
diversification advantages, rather than the portfolio of independent stocks, as resulted by the low correlation between commodity futures and stocks. This is shown by several previous studies, such as researches conducted by Bae and Karolyi (1994), Bahng and Shin (2003), and Badhani (2009) which suggested an asymmetric response between volatility spillover and return on the stock market. They found that the negative shock of one country would have greater impacts on other countries' stock market volatility, compared to the positive shock. In addition, they also found that stock volatility was higher when bad news was delivered at a good timing rather than when good news was delivered at a bad timing.

The occurance of volatility spillover between stock market and asymmetric response caused an unsatisfying stock market performance for investors who seek profit on stock investment. This is why investors look for another investment alternatives, one of them being commodity futures.

Diversification is done by investors to uncover or build an optimal portfolio, with certain return that can provide the lowest risk. However, it is not easy to determine the asset that can give investors diversification advantage in one investment portfolio. In order to identify potential diversification advantage in one investment portfolio consists of stock and commodity futures, author tested the existence of volatility spillover in both financial assets. By testing the existence of spillover, author can observe whether the shock that occurs in stock market will be transmitted to commodity future market, or conversely whether the shock that occurs in commodity futures market will be transmitted to stock market. If the result shows an insignificant parameter which is indicates the non-existing spillover, then investment portfolio that consists of stock and commodity future will provide diversification advantage so that investor will be able to consider including both assets in one investment portfolio to obtain optimal portfolio.

In this research, author uses stock return and commodity futures return, which are crude palm oil (CPO) and gold futures as variables of research. The data is obtained from two futures exchange in Indonesia: Jakarta Futures Exchange and Indonesia Commodity $\&$ Derivatives Exchange. The lack of empirical studies about volatility spillover on stock and commodity futures in Indonesia makes this research an interesting study.

\section{LITERATURE REVIEW}

Investment can be divided into real investment and financial investment. Financial assets usually distinguish into three broad types: debt, equity, and derivatives (Bodie, Kane, \& Marcus, 2011). Financial derivative assets provides payoffs that are determined by the price of other assets such as stock, bond, foreign exchange, index, and commodity. Futures contract is one of derivatives transaction in the form of agreement to buy or sell assets at specified time and price. One of the assets is commodity. A futures contract calls for delivery of an asset (or in some cases, its cash value) at a specified delivery or maturity date, for an agreed-upon price, called the futures price, to be paid at contract maturity (Bodie, Kane, \& Marcus, 2011).

Generally, trader who transacts at futures market can be categorized as hedger and speculator. Hedger is a futures trader who is interested in reducing risk (Hull, 1997). The risks can come from the changes of price, exchange rate, interest rate, inflation, etc. To protect the business from the risk of price changes, hedger do the hedging by transferring the risk to trader who expects a profit from price changes. In practice, when approching 
the delivery time, hedger will close the position of futures contract and transact in real market. This is done to maintain the potentially benefit that he already has.

Unlike hedger who wants to reduce the strain of price changes onunderlying asset, speculator expects to take an advantageous position in the market (Hull, 1997). Speculators are willing to bear the risk that hedger does not want to bear. If speculators believe that price will rise, they will take the long position. Instead, speculators will take short position if they believe that the price will decline so that speculators can take the profit by closing their position. Thus, futures trading can be a tool of managing the risks of price changes through hedging. By hedging, the loss that may arise from price fluctuation in physical market can be reduced by gaining profit in futures market, and vice versa.

Almost all investments contain risks. Risk can be defined as the uncertainty of the expected return (Bacon, 2008). Risks borne by investors can be reduced by diversification, which means putting a lot of assets in the investment portfolio so the pressure on one asset can be limited (Bodie, Kane, \& Marcus, 2011). By diversification, investors expect maximum returns with tolerable certain risks. Following the Markowitz model (Markowitz, 1952), diversification advantage will be obtained when there is risk reduction as reflected by the decrease of standard deviation. Standard deviation of the portfolio will be lower if the correlation coefficient between return assets in the portfolio is lower.

Current process of globalization and financial market liberalization cause financial markets to be more integrated. Such financial integration leads to interdependence between markets, therefore the market will have the same response to the shock (Chan Sok-Gee \& Karin, 2010). Volatility or shock that occurs in one market can be immediately transmitted to other markets. In such situations, the correlation of performance between market can be attributed to volatility spillover. Therefore, the phenomenon of volatility spillover may be related to the advantage of diversification in the decision of portfolio establishment.

Analyzing the period of July 1959 - December 2004, Gorton and Rouwenhorst (2006) tested the correlation between commodity futures returns with stocks and bonds in several periods, i.e. monthly, quarterly, one-year, and five-year. In all periods, except for monthly periods, commodity returns have negative correlations with stocks and bonds. The longer the period, the greater the negative correlation was. Research conducted by Gorton and Rouwenhorst also found that during the 5\% of the month when the stock market experienced its worst performance, i.e. when stocks fell on average by $8.98 \%$ per month, commodity futures still experienced a positive return of $1.03 \%$ per month. In addition, during $1 \%$ of the month when the stock market experienced its lowest performance, i.e. when stocks fell on average by $13.87 \%$ per month, commodity futures still gave a positive return: the return with an average of $2.36 \%$ per month.

Although not all risks can be diversified, commodity futures show a diversification effect on systemic risk during the recession stage. During early stage of expansion, stocks and bonds show a negative return while commodity futures shows a positive return. Furthermore, during the later stage of expansion, stocks and bonds present a positive return while commodity futures shows a negative return. This shows that the diversification advantage of commodity futures runs well when needed, i.e. whenever stock returns and bonds are negative, commodity futures return remains positive.

Conover, Jensen, Johnson, and Mercer (2010) conducted a study in the period of December 1970 to August 2007 to evaluate the performance of several portfolio alternatives, i.e. portolio that consists of stocks and commodity futures with 5\%,10\%, and 
$15 \%$ allocation in commodity futures. The results showed that investment portfolio with $5 \%$ allocation was not sufficient to generate significant diversification advantage. In contrast, diversification advantage would be more significant if it includes $10 \%$ and $15 \%$ allocation of commodity future in the investment portfolio.

In line with two previous studies, Hammoudeh, Nguyen, Reboredo, and Wen (2014) conducted research on commodity futures in China from July 2000 to May 2013. Using the daily returns of stocks and commodities futures and using the copula analysis method, it was found that there was a correlation which is small and positive between the two instruments. This makes commodity futures as a diversification instrument.

Although some studies have found the diversification advantage in commodity futures, other studies showed different results. Xiao-Ming Li, Zhijie Du and Bing Zhang (2011) used data of S \& P Goldman Sach Commodity Index and 45 stock indexes in developed and developing countries from January 2000 to December 2010 using the dynamic conditional correlation method. The results showed that in the long term, almost all stocks have a high correlation with commodity futures, especially after the global financial crisis. In addition, the correlation also increased when stock market volatility increased. This makes the advantage of diversification disappear. The dissapearance of this diversification advantage might be caused by increasing integration between commodity futures and stocks and more investors holding both instruments in their portfolio.

Demiralay and Ulusoy (2014) analyzed the correlation of volatility between commodity futures and stocks using the asymmetric dynamic conditional correlation (ADCC) model. They used weekly return data from January 1992 to December 2013. The results showed strong interdependence between commodity futures and stocks. The correlation of energy, agriculture and metal commodity indices with stock index increased as both markets declined. This correlation basically increased after the global financial crisis. In addition, there was an increasing volatility correlation when stocks had high volatility. This implicated on the deteriorating of diversification advantage.

The lack of empirical study regarding diversification advantage on portfolio containing stock and commodity future in Indonesia is what makes this an interesting study. Moreover by examining the spillover of volatility from stock to commodity future and commodity future to stock in Indonesia, this will surely be an intriguing study, especially in finance.

\section{RESEARCH METHOD}

This study aims to investigate the phenomenon of volatility spillover between two financial markets namely stock market and commodity futures market. Particularly, this research will examine whether the shock that occurs in one market will be transmitted to other markets. Commodity futures markets that became the object of this research are $\mathrm{CPO}$ futures and gold futures. Both of these commodities are used because they are more liquid than other commodities. CPO futures are commodity futures traded multilaterally in futures exchanges, namely Indonesia Commodity and Derivative Exchange, while gold futures are commodity futures traded bilaterally, referring to London Loco gold, and transacted through alternative trading system mechanisms at the Jakarta Futures Exchange. 
The price used in CPO futures is the price at the nearest delivery month for each day, while the price used in gold futures is denominated in dollars and converted into rupiah with fixed rate of 1 US $\$=$ Rp10,000. In addition, author assumes that investors hold long positions and hold only one contract.

Return of commodity futures is formulated as follows:

Return $=\frac{\text { Daily Return }}{\text { Initial Margin }+ \text { Margin Call }}$

where:Daily return $=\left(P_{t}-P_{t-1}\right) x$ number of contract $x$ unit of contract

The dataused in this study is daily time series data from September 16, 2010 to September 30, 2015 which was obtained from several websites. Sectoral index data obtained from http://www.duniainvestasi.com, while futures CPO price data obtained from the official website of Indonesia Commodity and Derivatives Exchange (http://www.icdx.co.id) which is processed by taking the price at the nearest delivery month for each day. Meanwhile, gold futures price data obtained from the Jakarta Futures Exchange.

Time series data, especially in financial sector, mostly have inconstant volatility. Variables are considered to have time-varying volatility characheristic if the value of those variables promptly changes from one period to another in unpredictable behaviours. Meanwhile, time-varying volatility arises when large changes are followed by more massive changes, or small changes followed by lesser changes in a period (Hill, Griffiths $\&$ Lim, 2012). The volatility and time-varying volatility that occur in financial data cause inconstant residual variance and fluctuating from one period to another (heteroskedastic).

The heteroskedatic behaviour requires a model that is able to overcome data problem, which has inconstant residual variance. Therefore, before developing the proper model specification to estimate volatility spillover between stock market and derivative markets, the author will conduct a series of diagnostic tests to identify the characteristics of the data used in this study. The presence of time-varying volatility characteristics in the research data leads the author to use Generalized Autoregressive Conditional Heteroskedastic (GARCH) analysis method in estimating and testing the existence of volatility spillover on stock and commodity futures.

In this study, the GARCH model specification is developed to investigate the volatility spillover between stock exchange and commodity futures exchange. Specification of GARCH model to investigate the transmission of volatility from commodity futures exhange to stock exchange is as follows:

$$
\begin{gathered}
\text { ragri }_{t}=\mu+\sum_{j=1}^{p} \alpha_{j} \text { ragri }_{t-j}+\sum_{j=1}^{q} \beta_{j} e_{t-l j}+e_{t} \\
h_{t}=\delta+\alpha_{1} e^{2}{ }_{t-1}+\beta_{1} h_{t-1}+\emptyset_{1} \text { cpors }_{t}+\emptyset_{2} \text { cpors }_{t} D_{t}
\end{gathered}
$$

where: $D_{t}($ at equation 1$)=\left\{\begin{array}{l}1, \text { cpors }_{t}<0 \\ 0, \text { cpors }_{t}>0\end{array}\right.$

$$
\operatorname{rmining}_{t}=\mu+\sum_{j=1}^{p} \alpha_{j} \text { rmining }_{t-j}+\sum_{j=1}^{q} \beta_{j} e_{t-j}+e_{t}
$$




$$
h_{t}=\delta+\alpha_{1} e_{t-1}^{2}+\beta_{1} h_{t-1}+\emptyset_{1} \text { goldrs }_{t}+\emptyset_{2} \text { goldrs }_{t} D_{t} .
$$

where: $D_{t}$ (at equation 2) $=\left\{\begin{array}{l}1, \text { goldr }_{t}<0 \\ 0, \text { goldrs }_{t}>0\end{array}\right.$

Model specification to investigate the transmission of volatility from stock exchange to commodity futuresexchange is as follows:

$r c p o_{t}=\mu+\sum_{j=1}^{p} \alpha_{j} r c p o_{t-j}+\sum_{j=1}^{q} \beta_{j} e_{t-j}+e_{t}$

$h_{t}=\delta+\alpha_{1} e_{t-1}^{2}+\beta_{1} h_{t-1}+\emptyset_{3}$ agrirs $_{t}+\emptyset_{4}$ agrirs $_{t} D_{t} \ldots \ldots(3)$

where $: D_{t}($ at equation 3$)=\left\{\begin{array}{l}1, \text { agrirs }_{t}<0 \\ 0, \text { agrirs }_{t}>0\end{array}\right.$

$$
\begin{aligned}
\text { rgold }_{t} & =\mu+\sum_{j=1}^{p} \alpha_{j} \text { rgold }_{t-j}+\sum_{j=1}^{q} \beta_{j} e_{t-j}+e_{t} \\
h_{t} & =\delta+\alpha_{1} e^{2}{ }_{t-1}+\beta_{1} h_{t-1}+\emptyset_{3} \text { miningrs }_{t}+\emptyset_{4} \text { miningrs }_{t} D_{t}
\end{aligned}
$$

where $: D_{t}$ (at equation 4$)=\left\{\begin{array}{l}1, \text { miningrs } s_{t}<0 \\ 0, \text { miningrs } s_{t}>0\end{array}\right.$

Parameter $\emptyset_{1}$, at equations 1 and 2 are parameters that will be used to test the volatility spillover of commodity futures market to the stock market. Meanwhile, the parameter $\emptyset_{2}$ is used to test asymmetric phenomenon, whether negative shock from commodity futures will have a greater impact on stock volatility when compared to positive shock.

Otherwise, the volatility spillover from the stock market to commodity futures market will be examined through the parameter $\emptyset_{3}$ at equations 3 and 4 . The shocks that occur in the stock market itself are measured by the square value of the standardized residual resulting from the mean equation on the GARCH model (1.1 ) for return of agricultural stock $\left(\right.$ ragri $_{t}$ ), and mining stock $\left(\right.$ rmining $\left.g_{t}\right)$.Asymmetric phenomenon in spillover volatility will be done by testing parameter $\emptyset_{4}$.Positive sign in paramater $\emptyset_{4}$ shows that negative shock in stock market will have a larger impact in commodity futures exchange if compared by positive shock.

\section{RESULT AND DISCUSSION}

The following table shows the market performance for stock and commodity futures. Commodity futures that became the object of this research are CPO futures and gold futures, while the object for the stock market is the index of agriculture and mining stocks.

Table 1. The above statistics show that during the period of analysis, average return of stock index (both sectors of mining and agriculture index) is lower than the average return of CPO futures and gold futures. However, assets with a higher average return obviously have higher standard deviation. If this standard deviation is used as a statistic to measure risk, then investment in commodity futures indicates a greater risk characteristic than stocks. 
Table 1. Market Performance of Sectoral Stocks and Commodities Futures

\begin{tabular}{ccccc}
\hline & RAGRI & RMINING & RCPO & RGOLD \\
\hline Mean & 0.000019 & -0.000637 & 0.000991 & 0.010732 \\
Median & 0.000000 & 0.000000 & 0.000000 & 0.007269 \\
Maximum & 0.077661 & 0.070903 & 1.104575 & 6.694000 \\
Minimum & -0.085665 & -0.096603 & -0.941176 & -12.560000 \\
Std. Dev. & 0.014326 & 0.013864 & 0.163690 & 1.492977 \\
\hline
\end{tabular}

A series of analysis on the characteristics of data that is used in this study, either descriptively or through diagnostic test, showed that all research variables, i.e. agricultural stock return (ragri), return of mining stock (rmining), return of CPO futures (rcpo), and gold futures return (rgold), are not normally distributed. Statistics of kurtosis for all variables that shows numbers greater than three indicate that the data distribution for all variables follows the fat-tails characteristics. The statistics of skewness, kurtosis, and Jarque-Bera testing procedures indicate that the data is not normally distributed as shown in the following table.

Table 2. Statistics for Testing of Data Normality

\begin{tabular}{ccccc}
\hline & RAGRI & RMINING & RCPO & RGOLD \\
\hline Skewness & -0.02165 & -0.22956 & 0.01826 & -0.97250 \\
Kurtosis & 7.76739 & 8.16862 & 7.61307 & 11.84223 \\
Prob. JB & 0.00000 & 0.00000 & 0.00000 & 0.00000 \\
\hline
\end{tabular}

All research variables also show the characteristic of volatility clustering. This property is reinforced by the results of ARCH effect test that shows that all data has heteroskedastic nature, as shown in the following table.

Table 3. Research Variable of ARCH- LM Test

\begin{tabular}{ccccc}
\hline $\begin{array}{c}\text { Heteroskedasticity } \\
\text { Test: ARCH }\end{array}$ & RAGRI & RMINING & RCPO & RGOLD \\
\hline F-statistic & 22.1439 & 13.2506 & 12.0221 & 107.3219 \\
Obs*R-squared & 21.8088 & 13.1378 & 11.9309 & 99.3411 \\
Prob. F(1,1309) & 0.0000 & 0.0003 & 0.0005 & 0.0000 \\
Prob. Chi-Square(1) & 0.0000 & 0.0003 & 0.0006 & 0.0000
\end{tabular}

The use of the GARCH model specification to investigate the presence of spillover volatility between stock and commodity futures markets in this study is based on data characteristics that show fat-tails and heteroskedastic features as shown in Table 2 and Table 3 above. Univariate time series model approach is used in estimating the behaviour of returnon mean equation.

In choosing the mean equation specification for GARCH model, author performs tests to determine the ARMA model (p, q) with the best order. Selection of the model is based on the smallest value of Akaike Information Criterion (AIC) and Schwarz 
Information Criterion (SIC) and largest value of $\mathrm{r}^{2}$ adjusted. If two of the three criteria are met, thn author will choose the model as the best model so that it can be used in GARCH estimation.

Based on the above criteria, the author found that the model with the best order is ARMA $(3,1)$ and ARMA $(3,3)$. Diagnostic test that is performed on residual with lag 36 and alpha 0.05 indicatesthat residual iswhite noise-the residual has a constant mean and variance, and has no autocorrelation problems, except in lag 0. Thus GARCH $(1,1)$ ARMA $(3,4)$ will capture volatility spillover and asymmetric response of volatility spillover from CPO futures market to agriculture stock market. GARCH $(1,1)$ ARMA $(3,3)$ will capture volatility spillover and asymmetric response of volatility spillover from gold futures market to mining stock market.

Meanwhile, ARMA $(3,3)$ and ARMA $(2,4)$ are the model with best order for volatility spillover from the stock market to commodity futures market. Diagnostic tests performed on residuals with lag 36 and alpha 0.05 indicate that the residual is white noise, which has a constant mean and variance, and has no autocorrelation problems, except in lag 0 . Thus GARCH $(1,1)$ ARMA $(3,3)$ will capture volatility spillover and asymmetric response ofvolatility spillover from agriculture stock market to CPO futures and GARCH $(1,1)$ ARMA (,) will capture spillover volatility and asymmetric response ofvolatility spillover from stock market to_futures. The estimation result of GARCH model is shown in the following tables:

Table 4. Estimation Result of GARCH Model for Volatility Spillover from Commodity Futures (cpors) To Sectoral Stock (agriculture)

\begin{tabular}{cccc}
\hline \multicolumn{3}{c}{ Mean Equation } & \\
\hline Variable & Coefficient & Std. Error & Prob. \\
\hline Constant $(\mu)$ & 0.0000070 & 0.000421 & 0.9866 \\
AR $(3)(\alpha)$ & 0.140713 & 0.029720 & $0.0000^{*}$ \\
MA $(1)(\beta)$ & -0.045817 & 0.029065 & 0.1149 \\
& & \\
Variable & Variance Equation & & Prob. \\
Constant $(\delta)$ & Coefficient & Std. Error & $0.0034^{*}$ \\
ARCH effect $\left(\alpha_{1}\right)$ & 0.0000131 & 0.00000446 & $0.00000^{*}$ \\
GARCH effect $\left(\beta_{1}\right)$ & 0.112896 & 0.013902 & $0.00000^{*}$ \\
CPORS : Volatility & -0.00000125 & 0.019590 & 0.00000250 \\
spillover $\left(\emptyset_{1}\right)$ & & & 0.6164 \\
CPORSD : Asymmetry & -0.000000476 & 0.00000599 & 0.9366 \\
response on spillover & & & \\
volatility $\left(\emptyset_{2}\right)$ & &
\end{tabular}

* $\quad$ significant at alpha $=1 \%$

** $\quad$ significant at alpha $=5 \%$ 
Table 5. Estimation Result of GARCH Model for Volatility Spillover from Commodity Futures (goldrs) To Sectoral Stock (mining)

\begin{tabular}{cccc}
\hline \multicolumn{3}{c}{ Mean Equation } & \\
\hline Variable & Coefficient & Std. Error & Prob. \\
Constant $(\mu)$ & -0.000967 & 0.000180 & $0.0000^{*}$ \\
AR $(3)(\alpha)$ & 0.979106 & 0.005262 & $0.0000^{*}$ \\
MA $(3)(\beta)$ & -0.992236 & 0.002911 & $0.0000^{*}$ \\
& & \\
Variable & Variance Equation & & \\
Constant $(\delta)$ & Coefficient & Std. Error & Prob. \\
ARCH effect $\left(\alpha_{1}\right)$ & 0.0000146 & 0.0000029 & $0.0000^{*}$ \\
GARCH effect $\left(\beta_{1}\right)$ & 0.074655 & 0.009439 & $0.0000^{*}$ \\
GOLDRS : Volatility & 0.894495 & 0.011744 & $0.0000^{*}$ \\
spillover $\left(\emptyset_{1}\right)$ & -0.000000756 & 0.00000247 & 0.7592 \\
\hline
\end{tabular}

* $\quad$ significant at alpha $=1 \%$

$* * \quad$ significant at alpha $=5 \%$

Table 6. Estimation Result of GARCH Model for Volatility Spillover from Sectoral Stock (agrirs) To Commodity Futures (CPO)

\begin{tabular}{cccc}
\hline \multicolumn{3}{c}{ Mean Equation } & \\
\hline Variable & Coefficient & Std. Error & Prob. \\
Constant $(\mu)$ & 0.005541 & 0.004597 & 0.2281 \\
AR $(3)(\alpha)$ & -0.912511 & 0.029712 & $0.0000^{*}$ \\
MA $(3)(\beta)$ & 0.947204 & 0.024593 & $0.0000^{*}$ \\
& Variance Equation & & \\
Variable & Coefficient & Std. Error & Prob. \\
Constant $(\delta)$ & 0.018537 & 0.001791 & $0.0000^{*}$ \\
ARCH effect $\left(\alpha_{1}\right)$ & 0.087612 & 0.020626 & $0.0000^{*}$ \\
GARCH effect $\left(\beta_{1}\right)$ & 0.302846 & 0.070139 & $0.0000^{*}$ \\
AGRIRS : Volatility & -0.00491 & 0.000561 & $0.0000^{*}$ \\
spillover $\left(\emptyset_{3}\right)$ & & & \\
AGRIRSD : Asymmetry & & 0.001543 & $0.0000^{*}$ \\
response on spillover & -0.004844 & & \\
volatility $\left(\emptyset_{4}\right)$ & &
\end{tabular}

* $\quad$ significant at alpha $=1 \%$

** $\quad$ significant at alpha $=5 \%$ 
Table 7. Estimation Result of GARCH Model for Volatility Spillover from Sectoral Stock (miningrs) To Commodity Futures (gold)

\begin{tabular}{cccc}
\hline \multicolumn{5}{c}{ Mean Equation } & \\
\hline Variable & Coefficient & Std. Error & Prob. \\
\hline Constant $(\mu)$ & 0.004885 & 0.016685 & 0.7697 \\
AR $(2)(\alpha)$ & 0.043830 & 0.027390 & 0.1095 \\
MA $(4)(\beta)$ & -0.027670 & 0.025300 & 0.2741 \\
& Variance Equation & & \\
Variable & Coefficient & Std. Error & Prob. \\
Constant $(\delta)$ & 0.054628 & 0.004166 & $0.0000^{*}$ \\
ARCH effect $\left(\alpha_{1}\right)$ & 0.393336 & 0.018048 & $0.0000^{*}$ \\
GARCH effect $\left(\beta_{1}\right)$ & 0.716052 & 0.007575 & $0.0000^{*}$ \\
MININGRS : Volatility & -0.027961 & 0.003010 & $0.0000^{*}$ \\
spillover $\left(\emptyset_{3}\right)$ & & & \\
MININGRSD : & -0.075790 & 0.005927 & $0.0000^{*}$ \\
$\begin{array}{c}\text { Asymmetry response on } \\
\text { spillover volatility }\left(\emptyset_{4}\right)\end{array}$ & & & \\
\hline
\end{tabular}

* $\quad$ significant at alpha $=1 \%$

** $\quad$ significant at alpha $=5 \%$

Estimation results of volatility spillover from commodity futures to sectoral stock are shown in Table 4 and Table 5 through parameters $\emptyset_{1}$ and $\emptyset_{2}$. The insignificance of these parameters indicates that the shock that occurs in the CPO futures market will not be transmitted to sectoral stock (agriculture). Significant volatility spillover that is not observed also occurred in shock from the gold futures exchange to the sectoral mining stock exchange. This is indicated by the insignificance of parameter $\emptyset_{1}$ and parameter $\emptyset_{2}$ in table 5.

Otherwise, the shock in both mining and agricultural stock will be transmitted significantly to each of the gold and CPO commodity markets. The results of this inference are shown by the results of the test of parameters $\emptyset_{3}$ and $\emptyset_{4}$ in Table 6 and Table 7. In particular, the negative sign and significance of parameter $\emptyset_{4}$ in Tables 6 and 7 , indicates that volatility spillover intensity of agriculture and mining sectoral stock to commodity futuresexchanges occurs with an asymmetric pattern. Negative shocks that occur in the sectoral stock exchange will be transmitted with a stronger intensity than a positive shock transmission.

The existence of a significant volatility spillover from the agriculture and mining sectoral stock exchanges to the $\mathrm{CPO}$ and gold commodity futures shows that performance of stock market and commodity futures exchange will correlate with each other. Adopting Markowitz's portfolio optimization model, an investment portfolio that consists of stocks and commodities futures, will be a portfolio that does not minimize risk. The observed significant volatility spillover from sectoral exchanges to commodity futures exchange shows the significant interdependence between both of these markets. In this situation, the assets price in one market will correlate with the other markets. Particularly, the 
movement of asset price in commodity future exchanges will relate to the movement of asset price in stock market. In that condition, analyzing the market singularly regardless of the other (market) aspects, means ignoring important information about market behaviour. The changes of assets' price in one market are not only influenced by volatility shock that market, but also by the response to the price assets fluctuations in other markets. Understanding the spillover volatility between markets will implied to important matters such as daily risk management, and portfolio selection process by investors.

Therefore, studies regarding interdependency between financial markets have important implications towards asset allocation. In this context, Cappiello, Engle, and Sheppard (2008) emphasized that portfolio diversification can be achieved by with two strategies, which investing different types of assets having low correlation (negative), or investing the same type of assets through international market diversification. Hence, referring to the first strategy, the most important matter in asset allocation is how to identify the interdependency between finance markets, which in this study is done by investigating the spillover volatility phenomenon. Information regarding fluctuations in one market will be transmitted to other finance markets, will be significant to investment decisions.

The presence of significant empirical evidence of spillover between stock exchange and commodity futures exchange in this study is in line with the results of studies conducted by Xiao-Ming Li, Zhijie Du, and Bing Zhang (2011) which shows that in the long run almost all stocks have a high correlation to commodity futures, especially after the global financial crisis. In addition, the correlation also increases when stock market volatility increases. The high correlation between the market performance causes diversification advantage of stocks and commodities futures disappear. The empirical findings in this study also supports the results of studies conducted by Demiralay and Ulusoy (2014) which analyzed the correlation of volatility between commodity futures and stocks using the asymmetric dynamic conditional correlation (ADCC) model. The results show a strong interdependence between commodity futures and stocks with asymmetric patterns following market conditions and volatility conditions in the stock market. The correlation of energy, agriculture and metal commodity indices with stock indices rose stronger when both markets declined and when stock markets had high volatility. This situation clearly has implications for the deteriorating diversification advantage.

The existence of volatility asymmetric pattern in this study also shows that the volatility in the commodity futures market increases substantially after negative shocks rather than positive shock. Overreaction to bad news and underreaction to good news is often thought to be the cause of this asymmetric. The incoming good news or bad news to the market brings asymmetric implications for volatility. When negative news enters the market, asset prices will tend to enter the turbulent phase and increases the volatility, but if positive news enters the market, volatility tends to decline and the market enters in the tranquil phase. Asymmetric transmission process is an interesting finding in many studies.

As stated in Saadah (2013), significant volatility spillover finding does not only imply a reduction in the portfolio diversification advantage. Time-varying spillover volatility also implies that investors face an investment opportunity set that is also has time-varying characteristic. The next implication is the need to develop a new approach to solve the problem of dynamic portfolio selection for investors facing investment opportunity set that has time-varying characteristic. 


\section{CONCLUSIONS}

This research was conducted to examine the existence of volatility spillover between stock market and commodity futures market in Indonesia. Estimation results using data in the period 2010 to 2015 indicate the presence of significant volatility spillover from stock exchange to commodity futures exchange. In particular, the shocks that occur in sectoral stock indices such as agriculture and mining will soon be transmitted to the CPO and gold futures commodity futures. This concludes that both markets will have the same response to the incoming shock thus observation to the solid correlation of both market's performance is revealing.

An important implication of this finding is that if the sectoral stock index and commodity futures are incorporated into an investment portfolio, the investor will not have optimal diversification advantage. This is because there is a correlation between performance of both markets as a result of both markets having the same characteristics in response to the shock that is coming.

From a macroeconomic aspect, the observation of significant volatility spillovers between financial markets is closely linked to the stability of the financial system. The stability of the financial system itself is a condition that allows the national financial system to function effectively and efficiently, and is able to withstand internal and external shocks, thus contributing to the growth and stability of the national economy (Bank Indonesia, 2014). One of systemic risk that can disturb the stability of the financial system can come from elements in the domestic financial system, which are then transmitted to other financial elements or markets in the system. The findings of this study, which reinforce the results of previous studies on the phenomenon of volatility spillover, should be an early warning system that shocks to one element in the domestic financial system can be a source of systemic risk that could threaten the stability of the Indonesian financial system.

\section{REFERENCES}

Bae, K., and Karolyi, G.A. (1994). "Good News, Bad News, and International Spillovers of Stock Return Volatility between Japan and the US". Pacific-Basion Finance Journal, 2 (4), 405-438.

Badhani, K.N. (2009). "Response Asymmetry in Return and Volatility Spillover from the US to Indian Stock Market".The IUP Journal of Applied Finance, 15 (9), 22-45.

Bacon, C. (2008). Practical Portfolio Performance Measurement and Attribution, $2^{\text {nd }}$ ed., West Sussex, England.

Bahng, J.S., \& Shin, S. (2003). "Do Stock Price Indices Respond Asymmetrically? Evidence from China, Japan, and South Korea". Journal of Asian Economics, 14, 541-563.

Bank Indonesia. (2014). Peraturan Bank Indonesia Nomor 16/11/PBI/2014 Tentang Pengaturan dan Pengawasan Makroprudensial.

Bodie, Z., Kane, A. and Marcus, A.J. (2008). Essentials of Investments, $7^{\text {th }}$ ed., New York.

Bodie, Z., Kane, A. and Marcus, A.J. (2011). Investments and Portfolio Management, New York. 
Cappiello, L., Engle, R., and Sheppard, K. (2008). Asymmetric Dynamic in the Correlation of Global Equity and Bond Returns. European Central Bank Working Paper Series 204.

Chan Sok-Gee and Karim, M.Z.A. (2010). "Volatility Spillover of the Major Stock Markets in ASEAN-5 with the US and Japanese Stock Markets". International Research Journal of Finance and Economics, 44, 156-168.

Conover, C.M., Jensen, G.R., Johnson, R.R., and Mercer, J.M. (2010). "Is Now the Time to Add Commodities to Your Portfolio?'. The Journal of Investing, 19 (3), 10-19.

Creti, A., Joets, M., and Mignon, V. (2012). On the Links Between Stock and Commodity Markets' Volatility. Centure D'Etudes Prospectives Et D'Informations Internationales, No.2012-20.

Daskalaki, C. and Skiadopoulos, G.S. (2011). "Should Investors Include Commodities in Their Portfolio After All? New Evidence". Journal of Banking and Finance, 35, (10), 2606-2626.

Demiralay, S. and Ulusoy. (2014). Links Between Commodity Futures and Stock Market: Diversification Benefits, Financialization and Financial Crises. MPRA Paper, No. 59727.

Gorton, G. and Rouwenhorst, K.G. (2006). "Facts and Fantasies About Commodity Futures". Financial Analysts Journal, 62, 47-68.

Hammoudeh, S., Nguyen, D.C., Reboredo, J.C., and Xiaoqian Wen. (2014). "Dependence of Stock and Commodity Futures Markets in China: Implications For Portfolio Investment”. Emerging Markets Review, 21, 183-200.

Hill, R.C., Griffiths, W.E., and Lim, G.C. (2012). Principles of Econometrics, $4^{\text {th }}$ ed., Hoboken, New Jersey.

Hull, J.C. (1997). Options, Futures, and Other Derivatives, $3^{\text {rd }}$ ed.,Upper Saddle River, New Jersey.

Markowitz, H. (1952). "Portfolio Selection". The Journal of Finance, 7 (1),. 77-91.

Saadah, S. (2013). "Response Asymmetry in Spillover Volatility: An Empirical Study in the Indonesia and Singapore Stock Market". Indonesian Capital Market Review, 5 (2), 74-84.

Xiao-Ming Li, Zhijie Du, \& Bing Zhang. (2011). Correlation In Commodity Futures and Equity Markets Around The World: Long-Run Trend and Short-Run Fluctuation. 